\title{
Making Sense of Negative Findings from Mobile Attention Bias Modification Interventions for Individuals with Addictive Disorders: Quantitative Feasibility Study
}

Melvyn Zhang ${ }^{1}$, MBBS, MRCPsych; Jiangbo Ying ${ }^{1}$, MBBS, MRCPsych; Syidda B Amron ${ }^{1}$, Bsc(Hons); Zaakira Mahreen $^{1}$, Bsc(Hons); Guo Song ${ }^{1}$, PhD; Daniel SS Fung ${ }^{2}$, MBBS, MMED; Helen E Smith ${ }^{3}$, DM, FFPHM

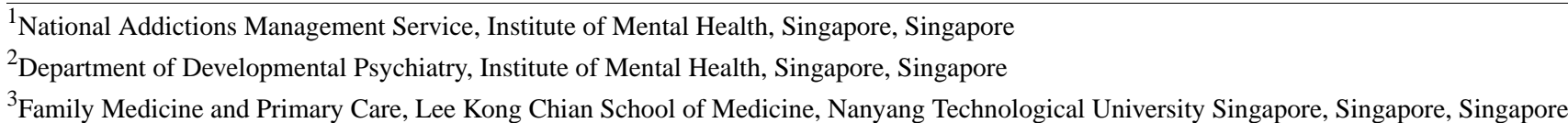

\section{Corresponding Author:}

Melvyn Zhang, MBBS, MRCPsych

National Addictions Management Service

Institute of Mental Health

10 Buangkok Green Medical Park

Singapore, 539747

Singapore

Phone: 6563802504

Email: melvynzhangweibin@gmail.com

\begin{abstract}
Background: Advances in experimental psychology have led to a better understanding of unconscious, automatic processes that result in individuals relapsing into their substance-using habits. While some reviews have demonstrated the effectiveness of bias retraining of these unconscious biases, there have been other reviews that have highlighted that bias retraining is not always effective. Other studies have revealed there was no baseline biases among some participants. An examination of mobile bias retraining interventions has also revealed mixed results, with some reporting effectiveness and others null findings. A recent feasibility and acceptability study, done by the authors, revealed that 53\% of participants have had no baseline biases and $21 \%$ of those with positive baseline biases did not have a positive change in magnitude following intervention.
\end{abstract}

Objective: The aim of this paper was to explore potential variables (demographic and clinical) that could account for the negative baseline biases in the prior feasibility and acceptability study, and to discuss some of the factors that could account for the absence of baseline biases. We also explored potential reasons for why there was no reduction in the magnitude of attentional biases among individuals with baseline biases.

Methods: Participants who were in the rehabilitation phase of their treatment were invited to participate. During the study they had to complete a set of baseline questionnaires, and on each day that they were on the ward they had to complete an attention bias assessment and modification task and rate their cravings using a visual analogue scale. Attention bias was deemed to be present if individuals had a positive score.

Results: In our study, 53\% (16/30) of individuals did not present with baseline attentional biases, and among those with positive baseline biases a total of $21 \%$ (3/14) of participants did not have a reduction in the overall magnitude of attentional biases. Chi-square analyses undertaken to compare the demographic characteristics of participants with and without baseline biases did not reveal any significant findings. However, with respect to clinical characteristics, those who had positive baseline biases had experimented with more substances.

Conclusions: Our study is one of the first to have explored negative findings in attention bias modification interventions for individuals with addictive disorders. We postulate that several factors could account for the absence of baseline biases and there being no changes following bias retraining. Future research ought to take into consideration these factors.

(JMIR Mhealth Uhealth 2019;7(11):e16325) doi: 10.2196/16325

\section{KEYWORDS}

attention bias; cognitive bias; psychiatry 


\section{Introduction}

Advances in experimental psychology over the years have led to a better understanding of unconscious, automatic processes [1] that result in individuals relapsing into their substance-using habits. Such processes include attentional biases and approach biases. Attentional biases refer to the automatic tendencies for attention to be preferentially allocated towards substance-related stimuli [2], whereas approach biases refer to the automated tendencies that result in individuals reaching out for substance stimuli [3]. The dual-process theoretical model explains that automatic biases develop as the chronic use of a substance results in increased automatic processing of the substance cue, with a resultant inhibition in the normal conscious cognitive control processes [4]. Tasks, such as the visual probe task and the Stroop task, are used in the assessment and modification of these automatic biases. The effectiveness of bias modification has been extensively evaluated. In a previous review, which considered studies involving participants with alcohol and tobacco use problems, bias modification interventions were deemed to be effective with a moderate effect size [5]. In a recent review from Heitman et al [6], they reported that only 10 of the identified 18 studies provided evidence for symptom change and effectiveness of attention bias modification. Of these 18 studies, 9 were focused on alcohol use, 6 were on nicotine use, and 3 were on opiate use [6]. Overall, the review found that multi-session interventions were more effective, especially for those who had adopted the alcohol attention control program [5].

Conventionally, attention bias modification interventions have been delivered in the laboratory, but advances in electronic and mobile health technologies have transformed the delivery of these interventions [7]. Zhang et al [8], in a review of a mobile cognitive bias intervention, reported that there had been at least 7 studies reporting that using the intervention with new technologies was more effective. However, one study (Robinson et al [9]) examining attention bias modification among smokers reported bias training to be ineffective, as the mobile intervention did not produce any changes in attentional biases. Similarly, Zhu et al [10], in their study examining the effectiveness of a mobile-based, computerized, cognitive addiction-therapy intervention, reported that their intervention led to no reduction in overall attention biases despite there being improvements in cognitive impairment and impulse control. In our recently published feasibility and acceptability study of a mobile attention bias intervention for inpatients with various addictive disorders (alcohol, opioids, cannabis, or stimulants) [11], we found that $16 / 30$ participants $(53 \%)$ did not have baseline attentional biases. Among those with baseline biases, attentional retraining did reduce the magnitude of the biases in all but three of the participants [11].

Negative findings are common in attention bias modification interventions. Negative findings are found in two contexts: at baseline assessment where there is an absence of biases, and when bias retraining fails to reduce the magnitude of attentional biases. Negative findings (the absence of effectiveness of bias modification) were highlighted in Heitman et al's [6] review of the effectiveness of bias retraining for individuals with opioid use disorders. Sharpe [12], in his commentary, highlighted a recent study involving attention bias modification for pain in children which also had negative findings. In this study [13], participants did not present with baseline biases. One of the factors that Sharpe [12] highlighted was that the experimental procedure was not appropriate for children, and prior meta-analysis has highlighted the need to present stimulus of longer presentation rates [14] for these biases to be detected. Factors like the quantity and frequency of substance use and cravings could also affect the magnitude of attentional biases [15].

In our prior feasibility and acceptability study, there were at least $53 \%(16 / 30)$ of individuals who did not present with baseline biases, and of the participants with baseline biases, $21 \%$ (3/14) did not have a reduction of biases following bias intervention [10]. Thus, the aim of this paper is to explore potential variables (demographic and clinical) that could account for negative baseline biases, and to discuss some of the factors that could account for the absence of baseline biases. We also explored potential reasons for there to be no reduction in the magnitude of attentional biases among individuals with baseline biases. An exploration of these negative findings is pertinent, as it has a consequential implication on future attention bias research.

\section{Methods}

\section{Overview}

The methods for this study have been previously published as a study protocol [16] and in Zhang's published feasibility and acceptability study [11]. Participants, who were in the rehabilitation phase of their treatment program at the National Addictions Management Service, Institute of Mental Health, were invited to participate. Participants who agreed to participate completed an informed consent form. The minimum recruitment target for the study was set at 30 participants.

\section{Ethical Approval}

This study has been approved by the National Healthcare Group's Domain Specific Research Board with the following reference number (2018/00316) on May 2, 2018.

\section{Inclusion and Exclusion Criteria}

Patients were included in the study if they were aged between 21-65 years old, were diagnosed with a primary psychiatric disorder of alcohol, opioid, cannabis, stimulants, or polysubstance dependence, were diagnosed with polysubstance dependence, with alcohol, opioid, cannabis or stimulants as the main substance of use, were able to read and write in English, and were capable of using a smartphone or tablet device. Patients were excluded from the study if they had a known history of cognitive impairment or dementia, if they had a history of seizures or a prior history of withdrawal seizures, if they had a history of migraines triggered by flashing lights, and if they had any moderate to severe comorbid psychiatric disorders based on clinical assessment. 


\section{Measures}

Upon recruitment into the study, baseline demographic and clinical information were acquired from the participants, including: nationality, gender, marital status, race, religion, highest level of education, housing conditions, current substance use, previous treatment history, chronic diseases (psychiatric or physical disorders), and any current psychiatric medication use. Participants also completed the modified Addiction Severity Index (ASI)-Lite, the Severity of Drug Dependence Scale (SDS), and the Short Form (SF-12) questionnaires. The ASI-Lite collects information about the participants' drug and alcohol use. All participants were asked about their alcohol and substance use in the last 30 days, in the last last month, and over their lifetime. The SDS questionnaire has 5 questions, all of which are focused on the psychological components of dependence. The SF-12 assessed the participants' self-reported quality of life.

Upon the completion of these questionnaires, participants were oriented on how they should use the application. On the first day of the intervention, participants were required to undertake an assessment task, then an intervention task, and then rest for 15 minutes before completing another assessment task. On the subsequent days of the intervention, participants were asked to complete an intervention task and then rest for 10 minutes before completing the assessment task. All participants were also asked to complete a visual-analogue craving scale before and upon the completion of each of the bias modification tasks. Participants were to undertake the tasks only if it was a weekday and were exempted from undertaking these tasks on weekends or public holidays.

In the assessment task, participants were presented with a central fixation cross for 500 milliseconds. Following the disappearance of the fixation cross, they were presented with a set of images, with one image being a substance image and the other a neutral image. The images would then disappear, and a probe would replace the position of one of these images. Participants were instructed to indicate the position of the probe by pressing on buttons within the application as rapidly as they could. In the assessment task, the probe would replace the substance-related image and the neutral image equally. In the intervention task, the probe would always replace the neutral image for the successful retraining of the attentional processes.

\section{Statistical Analyses}

Data collated was analyzed using SPSS Version 22 (IBM Corp, Armonk, New York, United States). Baseline demographic information of the subjects was summarized using descriptive statistics. The presence of attentional biases was determined based on the mean reaction times taken to respond to the position of the probes that replaced either the drug or neutral stimuli. The formula used for the computation of attentional biases was , where $\mathrm{T} 1 \mathrm{refers}$ to the time for probes that replaced the neutral stimulus, $\mathrm{n} 1$ refers to the number of trials for probes that replaced the neutral stimulus, T0 refers to the time for probes that replaced the substance stimulus, and N0 refers to the number of trials for probes that replaced the substance stimulus. A chi-square test was conducted to compare the demographic characteristics of those with and without baseline attentional biases.

\section{Results}

\section{Summary}

40 participants were screened and invited to participate in the study, of which 10 declined, thus leaving 30 who participated. A total of 11 of these participants failed to complete all the planned interventions, 10 of whom elected for premature discharge from the ward and 1 who withdrew from the study following the initial intervention. Table 1 (previously published in Zhang et al's feasibility and acceptability study) [11] provides an overview of the baseline attention bias scores for each of the participants and their change in scores across time.

\section{Baseline Attentional Biases}

It is evident from Table 1 that only 14/30 participants presented with positive attentional biases at baseline. The remaining 16 participants did not have any underlying attentional biases.

\section{Changes in Attentional Biases Over Time for Individuals With Positive Baseline Biases}

Among those with baseline attention biases, there was a general decrease in their attentional bias scores from baseline till the end of the intervention, except for three participants (numbers 8,19 , and 20). The changes in attentional biases scores ranged from 12.0 to 409.5 milliseconds.

Participants with and without baseline attentional biases were compared. Table 2 provides an overview of the baseline demographic characteristics of participants with and without attentional biases at baseline. The mean age of those with positive baseline attention bias was 46.3 years old, while those without attention bias had a mean age of 45.8 years. In terms of substance use, among those with positive baseline attention bias, 3 were diagnosed with alcohol use, 9 with opioid use, and 2 with stimulant use. Among those without baseline attention bias, 3 were diagnosed with alcohol use, 8 with opioids use, 2 with cannabis use, and 3 with stimulant use. Most of the participants were Singaporean. There was one female in the positive group and three females in the negative group. Most of the participants had a primary or secondary school education, and most were unemployed. Physical disorders were more common (43.8\%) among those with negative baseline attention bias. The mean scores for the severity of substance dependence were comparable (10.93 for the positive group and 10.31 for the negative group). 
Table 1. Overview of baseline attention bias scores and changes in scores over time.

\begin{tabular}{|c|c|c|c|c|c|c|c|c|}
\hline Participant & Drug & Baseline & $\begin{array}{l}\text { Post first ses- } \\
\text { sion }\end{array}$ & $\begin{array}{l}\text { Post second } \\
\text { session }\end{array}$ & $\begin{array}{l}\text { Post third } \\
\text { session }\end{array}$ & $\begin{array}{l}\text { Post fourth } \\
\text { session }\end{array}$ & $\begin{array}{l}\text { Post fifth } \\
\text { session }\end{array}$ & $\begin{array}{l}\text { Overall change in atten- } \\
\text { tional bias }\end{array}$ \\
\hline 001 & Stimulants & 30.3 & 70.6 & 36.3 & 9.3 & -23.6 & 13.3 & 17.0 \\
\hline $002^{\mathrm{a}}$ & Stimulants & -22.4 & -23.4 & -11.7 & $-\mathrm{b}$ & - & - & 10.7 (increased) \\
\hline 003 & Stimulants & 6.7 & -3.6 & -28.9 & -11.3 & 4.1 & -7.3 & 14.0 \\
\hline $004^{\mathrm{c}}$ & Opioid & 32.1 & 28.7 & 12.2 & 31.2 & 20.1 & - & 12.0 \\
\hline $005^{\mathrm{c}}$ & Alcohol & 91.2 & -23.3 & -37.4 & -5.3 & -33.2 & - & 124.4 \\
\hline $006^{\mathrm{c}}$ & Opioid & 98.9 & 33.4 & 14.5 & -9.7 & -31.5 & - & 130.4 \\
\hline 007 & Stimulants & -30.5 & -13.5 & -23.4 & -27.7 & -28.2 & -7.6 & 22.9 (increased) \\
\hline $008^{\mathrm{a}}$ & Opioids & 58.7 & 85.1 & - & - & - & - & 26.4 (increased) \\
\hline $009^{\mathrm{a}}$ & Opioids & 25.8 & 13.5 & - & - & - & - & 12.3 \\
\hline 010 & Cannabis & -9.9 & -20.7 & -54.6 & -14.1 & -22.9 & -48.4 & 38.5 \\
\hline 011 & Opioids & -30.9 & 2.4 & -15.4 & -7.4 & 14.2 & 7.3 & 38.2 (increased) \\
\hline $012^{\mathrm{a}}$ & Opioids & 0.7 & 34.8 & -15.3 & -52.4 & - & - & 53.1 \\
\hline 013 & Alcohol $^{\mathrm{d}}$ & -20.9 & -12.3 & - & - & -75.8 & -48.6 & 27.7 \\
\hline $014^{\mathrm{a}}$ & Alcohol & 397.7 & 44.2 & 45.3 & -32.0 & -11.7 & & 409.4 \\
\hline 015 & Cannabis & -7.7 & -40.5 & 8.6 & -33.6 & -31.8 & -50.3 & 42.6 \\
\hline $016^{\mathrm{a}}$ & Opioids & -27.4 & - & - & - & - & - & - \\
\hline 017 & Opioids & -42.5 & -64.8 & 63.4 & 8.9 & -15.5 & 26.7 & 69.2 (increased) \\
\hline 018 & Opioids & 27.9 & -17.8 & 3.2 & -22.6 & -104.6 & -9.2 & 37.1 \\
\hline $019^{\mathrm{a}}$ & Opioids & 3.8 & 35.1 & 13.7 & 32.4 & & & 28.6 (increased) \\
\hline 020 & Opioids & 10.1 & 9.4 & 105.2 & 54.1 & -1.7 & 20.3 & 10.2 (increased) \\
\hline 021 & Alcohol & 224.5 & 61.5 & 73.3 & 176.7 & 130.3 & 107.0 & 117.4 \\
\hline 022 & Opioids & -52.9 & 10.9 & 5.6 & 39.1 & 36.5 & 76.6 & 129.6 (increased) \\
\hline 023 & Opioids & -36.4 & 18.0 & 45.0 & 74.8 & 35.9 & 41.3 & 77.7 (increased) \\
\hline $024^{\mathrm{a}}$ & Opioids & -16.9 & 45.2 & 1.49 & 3.8 & 33.9 & - & 50.8 (increased) \\
\hline $026^{\mathrm{a}}$ & Opioids & -77.1 & -82.5 & - & - & - & - & 5.4 \\
\hline 027 & Stimulants & -15.2 & -11.6 & 10.1 & -27.0 & -25.7 & -1.6 & 13.6 (increased) \\
\hline 028 & Alcohol & -33.3 & -29.4 & -48.3 & -10.9 & -15.6 & -11.6 & 21.8 (increased) \\
\hline $029^{\mathrm{a}}$ & Alcohol & -41.4 & -18.0 & 20.6 & 28.2 & - & - & 69.6 (increased) \\
\hline 030 & Opioids & 1.3 & 38.6 & 7.9 & 11.5 & 13.0 & -8.9 & 10.2 \\
\hline $031^{\mathrm{a}}$ & Opioids & -38.4 & -282.7 & -166.4 & -190.1 & - & - & 151.6 \\
\hline
\end{tabular}

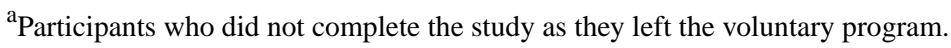

${ }^{\mathrm{b}}$ Not applicable.

${ }^{\mathrm{c}}$ There was a holiday during the assessment period and thus the maximum number of sessions completed was 4.

${ }^{\mathrm{d}}$ Due to a technical issue, Participant 13 was not administered an assessment task following the second intervention so the participant took another intervention task instead. Attentional bias assessment was performed only after the fourth session. 
Table 2. Baseline demographic characteristics $(n=30)$.

\begin{tabular}{|c|c|c|}
\hline Demographic characteristics & Positive baseline attention bias $(\mathrm{n}=14)$ & Negative baseline attention bias $(\mathrm{n}=16)$ \\
\hline Age (years), mean (SD) & $46.3(12.7)$ & $45.8(10.7)$ \\
\hline \multicolumn{3}{|l|}{ Substance use, n (\%) } \\
\hline Alcohol & $3(21)$ & $3(19)$ \\
\hline Opioids & $9(64)$ & $8(50)$ \\
\hline Cannabis & $0(0)$ & $2(13)$ \\
\hline Stimulants & $2(14)$ & $3(19)$ \\
\hline \multicolumn{3}{|l|}{ Nationality, n (\%) } \\
\hline Singaporean & $12(86)$ & $15(94)$ \\
\hline Others & $2(14)$ & $1(6)$ \\
\hline \multicolumn{3}{|l|}{ Gender, n (\%) } \\
\hline Male & $13(93)$ & $13(81)$ \\
\hline Female & $1(7)$ & $3(19)$ \\
\hline \multicolumn{3}{|l|}{ Race, $\mathbf{n}(\%)$} \\
\hline Chinese & $4(29)$ & $3(19)$ \\
\hline Malay & $6(43)$ & $7(38)$ \\
\hline Indian & $3(21)$ & $6(38)$ \\
\hline Others & $1(7)$ & $1(6)$ \\
\hline \multicolumn{3}{|l|}{ Education, $\mathrm{n}(\%)$} \\
\hline Primary education & $4(29)$ & $3(19)$ \\
\hline Secondary education & $7(50)$ & $9(56)$ \\
\hline Junior college or polytechnic/technical studies & $1(8)$ & $4(25)$ \\
\hline Undergraduate studies & $2(14)$ & $0(0)$ \\
\hline \multicolumn{3}{|l|}{ Employment, n (\%) } \\
\hline Unemployed & $10(71)$ & $13(81)$ \\
\hline Part-time employment & $1(8)$ & $2(13)$ \\
\hline Full-time employment & $3(21)$ & $1(6)$ \\
\hline \multicolumn{3}{|l|}{ Housing, $\mathrm{n}(\%)$} \\
\hline Homeless & $4(29)$ & $2(13)$ \\
\hline 1 room & $4(29)$ & $4(25)$ \\
\hline 2 rooms & $2(14)$ & $0(0)$ \\
\hline 3 rooms & $1(7)$ & $2(13)$ \\
\hline 4 rooms & $0(0)$ & $7(44)$ \\
\hline 5 rooms & $2(14)$ & $0(0)$ \\
\hline Others & $1(7)$ & $1(6)$ \\
\hline Psychiatric disorders, n (\%) & $2(14)$ & $1(6)$ \\
\hline Physical disorders, n (\%) & $4(29)$ & $7(44)$ \\
\hline Severity of substance dependence scores, mean (SD) & $10.93(3.33)$ & $10.31(3.28)$ \\
\hline
\end{tabular}

Using chi-square $\left(\chi^{2}\right)$ analysis to compare the categorical $\left.P=.60\right)$, race $\left(\chi_{3}^{2}=1.014 ; P=.80\right)$, education status $\left(\chi_{3}^{2}=4.078\right.$; demographical variables amongst those with and without $P=.25)$, employment $\quad\left(\chi_{2}^{2}=1.598 ; \quad P=.45\right)$, baseline attentional biases, we found no significant differences $\quad$ accommodation/housing $\quad\left(\chi_{6}^{2}=11.92 ; \quad P=.06\right)$, psychiatric

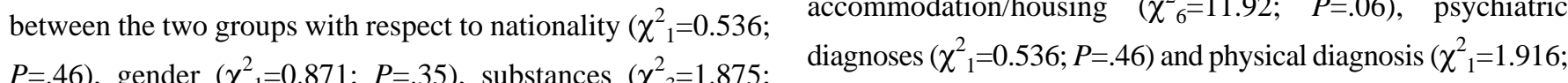
$P=.46)$, gender $\left(\chi_{1}^{2}=0.871 ; P=.35\right)$, substances $\left(\chi_{3}^{2}=1.875 ; \quad \begin{array}{l}\text { diagnoses }( \\ P=.38) \text {. }\end{array}\right.$ 
Table 3 and Table 4 provide an overview of participants with and without baseline attentional biases and their reported drug use, recorded on the modified ASI-Lite questionnaire. As evident from Table 2, Table 3, and Table 4, both the two participants with cannabis use disorder did not present with any baseline attentional biases. Most of the participants had started using their substance of abuse at a young age, and most of them were using daily prior to admission. Individuals in the group with positive baseline attention bias had experimented with more substances, as compared to individuals in the group without baseline attention bias.

Table 3. Substance use history of participants with positive baseline attention bias.

\begin{tabular}{|c|c|c|c|c|c|c|c|}
\hline Participant & Age & Baseline bias & Current drug & Drug history & Age of onset & $\begin{array}{l}\text { Age of problematic } \\
\text { use }\end{array}$ & $\begin{array}{l}\text { Frequency prior to } \\
\text { admission }\end{array}$ \\
\hline 001 & 46 & 30.3 & Stimulants & Polysubstance (9) ${ }^{\mathrm{a}}$ & 45 & 45 & $\begin{array}{l}\text { Daily (1-2 grams, } \\
\text { once per day) }\end{array}$ \\
\hline 003 & 35 & 6.7 & Stimulants & Polysubstance (7) & 31 & 31 & $\begin{array}{l}\text { Daily ( } 0.5 \text { grams, } \\
\text { once per day) }\end{array}$ \\
\hline 004 & 46 & 32.1 & Opioids & Polysubstance (12) & 14 & 17 & $\begin{array}{l}\text { Daily }(30-40 \mathrm{~mL} \text {, } \\
1-2 \text { times per day) }\end{array}$ \\
\hline 005 & 26 & 91.2 & Alcohol & Alcohol (1) & 20 & 21 & $\begin{array}{l}\text { Daily }(750 \mathrm{~mL}, 2- \\
3 \text { times per day) }\end{array}$ \\
\hline 006 & 64 & 98.9 & Opioids & Polysubstance (11) & 20 & 22 & $\begin{array}{l}\text { Daily ( } 2 \text { Straws, } \\
\text { once daily) }\end{array}$ \\
\hline 008 & 60 & 58.7 & Opioids & Polysubstance (4) & 13 & 13 & $\begin{array}{l}\text { Daily (1 Straw, } 2 \\
\text { times daily) }\end{array}$ \\
\hline 009 & 28 & 25.8 & Opioids & Polysubstance (5) & 17 & 19 & $\begin{array}{l}\text { Daily ( } 1.5 \text { straws, } \\
6 \text { times daily) }\end{array}$ \\
\hline 012 & 28 & 0.7 & Opioids & Polysubstance (5) & 18 & 25 & $\begin{array}{l}\text { Daily ( } 5 \text { tablets, } 5 \\
\text { times daily) }\end{array}$ \\
\hline 014 & 61 & 397.7 & Alcohol & Polysubstance (5) & 13 & 27 & $\begin{array}{l}\text { Daily ( } 3 \text { tall cans, } \\
2 \text { times daily) }\end{array}$ \\
\hline 018 & 54 & 27.9 & Opioids & Polysubstance (5) & 34 & 34 & $\begin{array}{l}\text { *Patient did not fill } \\
\text { up }\end{array}$ \\
\hline 019 & 57 & 3.8 & Opioids & Polysubstance (3) & 40 & 40 & $\begin{array}{l}\text { Daily }(90 \mathrm{~mL} \text {, once } \\
\text { per day) }\end{array}$ \\
\hline 020 & 45 & 10.1 & Opioids & Polysubstance (4) & 23 & 23 & $\begin{array}{l}\text { Daily ( } 1 \text { straw, } 3 \\
\text { times daily) }\end{array}$ \\
\hline 021 & 50 & 224.5 & Alcohol & Alcohol \& tobacco (2) & 15 & 50 & $\begin{array}{l}\text { Daily ( } 8 \text { cans, once } \\
\text { daily) }\end{array}$ \\
\hline 030 & 48 & 1.3 & Opioids & Polysubstance (3) & 16 & 16 & $\begin{array}{l}\text { Daily (4 Straws, } 4 \\
\text { times daily) }\end{array}$ \\
\hline
\end{tabular}

$\mathrm{a}(\mathrm{n})$ : This refers to the total number of substances the individual has experimented with. 
Table 4. Substance use history of participants with negative baseline attention bias

\begin{tabular}{|c|c|c|c|c|c|c|c|}
\hline Participant & Age & Baseline bias & Current drug & Drug history & Age of onset & $\begin{array}{l}\text { Age of problematic } \\
\text { use }\end{array}$ & $\begin{array}{l}\text { Frequency prior to } \\
\text { admission }\end{array}$ \\
\hline 002 & 44 & -22.4 & Stimulants & Polysubstance (4) ${ }^{\mathrm{a}}$ & 38 & 40 & $\begin{array}{l}\text { Daily (Unknown } \\
\text { quantity, } 6 \text { times } \\
\text { daily) }\end{array}$ \\
\hline 007 & 32 & -30.5 & Stimulants & Polysubstance (3) & 29 & 30 & $\begin{array}{l}\text { Daily ( } 0.3 \text { grams, } \\
5 \text { times daily) }\end{array}$ \\
\hline 010 & 59 & -9.9 & Cannabis & Polysubstance (5) & 59 & 59 & $\begin{array}{l}\text { Daily ( } 2 \text { joints } \\
\text { once per day) }\end{array}$ \\
\hline 011 & 50 & -30.9 & Opioids & Polysubstance (3) & 24 & 24 & $\begin{array}{l}\text { Daily (4 straws, } 4 \\
\text { times per day) }\end{array}$ \\
\hline 013 & 42 & -20.9 & Alcohol & $\begin{array}{l}\text { Alcohol and tobacco } \\
\text { (2) }\end{array}$ & 18 & 18 & $\begin{array}{l}\text { Daily (3-4 bottles, } \\
3 \text { times per day) }\end{array}$ \\
\hline 015 & 57 & -7.7 & Cannabis & Polysubstance (7) & 57 & 57 & $\begin{array}{l}\text { Daily ( } 1 \text { joint, } 20 \\
\text { times per day) }\end{array}$ \\
\hline 016 & 47 & -27.4 & Opioids & Polysubstance (6) & 17 & 17 & $\begin{array}{l}\text { Daily ( } 1 \text { joint, } 6-7 \\
\text { times per day) }\end{array}$ \\
\hline 017 & 63 & -42.5 & Opioids & Polysubstance (4) & 16 & 17 & $\begin{array}{l}\text { Daily ( } 0.5 \text { straws, } \\
3 \text { times per day) }\end{array}$ \\
\hline 022 & 43 & -52.9 & Opioids & Polysubstance (6) & 16 & 17 & $\begin{array}{l}\text { Daily ( } 2 \text { straws, } 2 \\
\text { times per day) }\end{array}$ \\
\hline 023 & 54 & -36.4 & Opioids & Polysubstance (6) & 15 & 16 & $\begin{array}{l}\text { Daily ( } 3 \text { straws, } 10 \\
\text { times per day) }\end{array}$ \\
\hline 024 & 46 & -16.9 & Opioids & Tobacco \& heroin (2) & 17 & 21 & $\begin{array}{l}\text { Daily ( } 7 \text { straws, } 4 \\
\text { times per day) }\end{array}$ \\
\hline 026 & 57 & -77.1 & Opioids & Tobacco \& heroin (2) & 17 & 28 & $\begin{array}{l}\text { Daily ( } 1 \text { straw, } 2 \\
\text { times per day) }\end{array}$ \\
\hline 027 & 31 & -15.2 & Stimulants & Polysubstance (9) & 17 & 25 & $\begin{array}{l}\text { Daily ( } 0.3 \text { grams } \\
\text { throughout the } \\
\text { day) }\end{array}$ \\
\hline 028 & 44 & -33.3 & Alcohol & $\begin{array}{l}\text { Alcohol and tobacco } \\
\text { (2) }\end{array}$ & 17 & 28 & $\begin{array}{l}\text { Daily }(750 \mathrm{~mL}, 16- \\
18 \text { times per day) }\end{array}$ \\
\hline 029 & 39 & -41.4 & Alcohol & Polysubstance (3) & 14 & 30 & $\begin{array}{l}\text { Daily (9-10 cans, } 9 \\
\text { times per day) }\end{array}$ \\
\hline 031 & 25 & -38.4 & Opioids & Polysubstance (8) & 20 & 20 & $\begin{array}{l}\text { Daily (1 straw, } 2 \\
\text { times per day) }\end{array}$ \\
\hline
\end{tabular}

a(n): This refers to the total number of substances the individual has experimented with.

\section{Discussion}

\section{Primary Findings}

We are unaware of any other study that has examined negative findings in attention bias modification intervention for individuals with addictive disorders. In our study, 53\% (16/30) of individuals did not present with baseline attentional biases, and among those with positive baseline biases, $21 \%(3 / 14)$ of participants did not have a reduction in the overall magnitude of attentional biases. Chi-square analyses undertaken to compare the demographic characteristics of participants with and without baseline biases did not reveal any significant findings. However, with respect to clinical characteristics, those who had positive baseline biases had experimented with more substances. We postulate that there are four factors that could account for the absence of baseline biases: the period of abstinence, the images used in the mobile application, the stimulus timings, and the clinical characteristics of the participants. With regards to the lack of retraining effects, we theorize that this might be due to practice effects or to the novelty of the other neutral stimulus.

The lack of baseline biases we observed may be due firstly to the fact that our participants had received treatment and had been abstinent for at least seven days prior to being recruited into the study. This period of abstinence might have affected their baseline attentional biases. In most of the published studies $[17,18]$, participants who had been recruited were in the detoxification phase of treatment. In our study, participants were considered for the intervention only upon the successful completion of their detoxification program. Participants who were in their detoxification phase were not recruited, as we anticipated that them having withdrawal symptoms might affect their ability to undertake the required interventions. The existing 
medication-assisted detoxification was highly effective in ameliorating attentional biases among these participants. Psychotropic medications prescribed in the acute detoxification phase might have affected or reduced attentional biases. Dopaminergic and serotonergic agents (such as antipsychotics and antidepressants) could have reduced attention biases in the acute phase, as highlighted in Zhang et al's [19] prior review. Some of these medications might have been used for symptomatic relief of psychotic or affective symptoms in these individuals during the withdrawal phase. Unfortunately, in this current study we did not request ethical approval to extract information from the medical records, and thus the association between the prescription of medications and attentional biases cannot be determined.

Secondly, the nature of the images/stimuli used in our application may have contributed to a null finding at baseline assessment. The images used in the application may not be good representations of the substances participants were familiar with, and thus did not manage to capture their attention. This is in line with Field et al's [20] report that one of the key factors leading to the poor reliability of the visual probe task is that of the nature of the stimulus used. Field et al [20] highlighted the importance of personalization of the stimulus presented to the participants, as it is postulated that a stimulus that is relevant and identifiable to the participant could increase their baseline attentional bias score and provide evidence of greater change in the magnitude of attentional biases. Many of the images included in the mobile application were extracted from the internet via the United States Drug Enforcement Agency media library. Fewer images came from Singapore's Central Narcotics Bureau's website. It might be possible that the images included do not approximate the real object and are not realistic enough for participants.

Thirdly, as highlighted by Sharpe [12], the experimental procedure that we used in our study might have affected the detection of baseline biases, in regard to the duration of the presentation of the images. In our study, we presented the stimulus for 500 milliseconds, like most prior studies which had evaluated the reliability of the visual probe task $[21,22]$. We are aware that there have been other studies, such as those by Constantinou et al, Frankland et al, and two by Garland et al [21-24], that have presented the stimulus for as little as 200 milliseconds to as long as 1500 to 2000 milliseconds. It has been previously postulated in the literature that the short stimulus interval helped in the evaluation of automatic orientating tendencies, whereas the long stimulus interval helped in the evaluation of controlled attentional processing. In some of these previous studies [23-26], the stimulus was being presented to individuals at both a short and long stimulus interval. The fact that we had a fixed stimulus timing interval of 500 milliseconds might have resulted in us not capturing potentially controlled attentional processes, which might account for individuals not having baseline biases. It is thus of importance for there to be a review of stimulus timings that have been previously used and to correlate the timings with the effectiveness of bias detection and modification.

Lastly, with regards to the absence of baseline biases, Dean et al's [15] research has highlighted that clinical characteristics of participants modulate their baseline attentional biases. In our study, we did not manage to find any demographic variables that could account for the differences among those with baseline biases and those without. There were, however, more individuals in the group with positive baseline biases that had previously abused a larger quantity of substances. This observation is congruent with previous research, which reported that the frequency and quantity of drug use do moderate the magnitude of the attentional biases. Field et al [21], in their previous study, reported that there were more robust attentional biases among individuals who were heavy drinkers when the alcohol images were presented for 500 and 2000 milliseconds, respectively. In another study by Noel et al [27], the authors reported that there was an absence of attentional biases among those who were abstinent from alcohol use. It is evident from these studies that the amount of substance use affects the attentional biases, and this should be an important consideration when planning for future attention bias modification interventions for individuals with addictive disorders since there may be individuals who are abstinent and without baseline biases, so attention bias modification might not be appropriate for them. It is important that future studies consider evaluating individuals for baseline biases before administration of bias modification.

Regarding the negative findings among those with positive baseline attentional biases (ie, no impact of attentional retraining), we postulate that the absence of effects could be accounted for by practice effects. Thus, for some individuals, over the course of the intervention they have learnt to focus only on the position of the probe and not on the stimulus. There is also the possibility that the neutral stimulus might have appeared to be more novel and appealing to some individuals, which lead to an increased focus on the neutral stimulus and a resultant more rapid response in identifying probes that replace the neutral stimulus.

\section{Conclusions}

Our study is one of the first to have explored negative findings in attention bias modification interventions for individuals with addictive disorders. We postulate that there could be several factors that could account for the absence of baseline biases and there being no changes following bias retraining. Future research ought to take into consideration these factors, and it is especially pertinent for clinical studies to evaluate for baseline bias prior to administration of bias retraining interventions.

\section{Acknowledgments}

We would like to thank the National Addictions Management Service for providing finance support for this project. 


\section{Authors' Contributions}

MZ, JY, SBA, ZM, GS, DSSF, HES jointly conceptualized the study. MZ, SBA, ZM were involved in data collation. MZ and JY coded and analyzed the initial data. MZ, JY, SBA, ZM, GS, DSSF, HES reviewed the final dataset. MZ and HES jointly worked on and wrote up the initial draft of the manuscript. HES provided further comments, which aided MZ in formulating the second draft of the manuscript. All authors proofread and approved of the manuscript prior to publication.

\section{Conflicts of Interest}

None declared.

\section{References}

1. Zhang M, Ying J, Song G, Ho RC, Fung DS, Smith H. Attention Bias in Individuals with Addictive Disorders: Systematic Review Protocol. JMIR Res Protoc 2018 Feb 08;7(2):e41 [FREE Full text] [doi: 10.2196/resprot.9385] [Medline: 29422449]

2. Field M, Marhe R, Franken IHA. The clinical relevance of attentional bias in substance use disorders. CNS Spectr 2014 Jun;19(3):225-230. [doi: 10.1017/S1092852913000321] [Medline: 23663386]

3. Wiers RW, Rinck M, Kordts R, Houben K, Strack F. Retraining automatic action-tendencies to approach alcohol in hazardous drinkers. Addiction 2010 Feb;105(2):279-287. [doi: 10.1111/j.1360-0443.2009.02775.x] [Medline: 20078486]

4. Wiers R, Teachman B, De Houwer J. Implicit cognitive processes in psychopathology: an introduction. J Behav Ther Exp Psychiatry 2007 Jun;38(2):95-104. [doi: 10.1016/j.jbtep.2006.10.002] [Medline: 17112462]

5. Cristea I, Kok R, Cuijpers P. The Effectiveness of Cognitive Bias Modification Interventions for Substance Addictions: A Meta-Analysis. PLoS ONE 2016 Sep 92016 Sep;11(9):A.

6. Heitmann J, Bennik EC, van Hemel-Ruiter ME, de Jong PJ. The effectiveness of attentional bias modification for substance use disorder symptoms in adults: a systematic review. Syst Rev 2018 Oct 13;7(1). [doi: 10.1186/s13643-018-0822-6]

7. Zhang M, Ying J, Ho RC. Gamified Cognitive Bias Interventions for Psychiatric Disorders: Protocol of a Systematic Review. JMIR Res Protoc 2018 Oct 16;7(10):e10154 [FREE Full text] [doi: 10.2196/10154] [Medline: 30327292]

8. Zhang M, Ying J, Song G, Fung D, Smith H. Attention and Cognitive Bias Modification Apps: Review of the Literature and of Commercially Available Apps. JMIR Mhealth Uhealth 2018 May 24;6(5):e10034 [FREE Full text] [doi: 10.2196/10034] [Medline: 29793899]

9. Robinson C, Muench C, Brede E, Endrighi R, Szeto E, Sells J, et al. Effect of attentional retraining on cognition, craving, and smoking in African American smokers. Psychol Addict Behav 2017 Aug;31(5):636-646 [FREE Full text] [doi: 10.1037/adb0000286] [Medline: 28627913]

10. Zhu Y, Jiang H, Su H, Zhong N, Li R, Li X, et al. A Newly Designed Mobile-Based Computerized Cognitive Addiction Therapy App for the Improvement of Cognition Impairments and Risk Decision Making in Methamphetamine Use Disorder: Randomized Controlled Trial. JMIR Mhealth Uhealth 2018 Jun 20;6(6):e10292. [doi: 10.2196/10292]

11. Zhang M, Ying J, Amron S, Mahreen Z, Song G, Fung D, et al. A Smartphone Attention Bias App for Individuals With Addictive Disorders: Feasibility and Acceptability Study. JMIR Mhealth Uhealth 2019;7(9):e15465. [doi: 10.2196/preprints.15465]

12. Sharpe L. Attention bias modification for children. PAIN 2018;159(2):191-192. [doi: 10.1097/j.pain.0000000000001107]

13. Heathcote LC, Jacobs K, Van Ryckeghem DM, Fisher E, Eccleston C, Fox E, et al. Attention bias modification training for adolescents with chronic pain. PAIN 2018;159(2):239-251. [doi: 10.1097/j.pain.0000000000001084]

14. Cristea IA, Mogoa e C, David D, Cuijpers P. Practitioner Review: Cognitive bias modification for mental health problems in children and adolescents: a meta-analysis. J Child Psychol Psychiatr 2015 Jan 30;56(7):723-734. [doi: 10.1111/jcpp.12383]

15. Dean AC, Nurmi EL, Moeller SJ, Amir N, Rozenman M, Ghahremani DG, et al. No effect of attentional bias modification training in methamphetamine users receiving residential treatment. Psychopharmacology 2018 Nov 10;236(2):709-721. [doi: $10.1007 / \mathrm{s} 00213-018-5100-8]$

16. Zhang M, Ying J, Amron SB, Mahreen Z, Song G, Fung DS, et al. A Smartphone Attention Bias Intervention for Individuals With Addictive Disorders: Protocol for a Feasibility Study. JMIR Res Protoc 2018 Nov 19;7(11):e11822. [doi: 10.2196/11822]

17. Manning V, Staiger PK, Hall K, Garfield JB, Flaks G, Leung D, et al. Cognitive Bias Modification Training During Inpatient Alcohol Detoxification Reduces Early Relapse: A Randomized Controlled Trial. Alcohol Clin Exp Res 2016 Aug 04;40(9):2011-2019. [doi: 10.1111/acer.13163]

18. Eberl C, Wiers RW, Pawelczack S, Rinck M, Becker ES, Lindenmeyer J. Approach bias modification in alcohol dependence: Do clinical effects replicate and for whom does it work best? Developmental Cognitive Neuroscience 2013 Apr;4:38-51. [doi: 10.1016/j.den.2012.11.002]

19. Zhang MW, Ying JB, Song G, Fung DSS, Smith HE. Recent Advances in Attention Bias Modification for Substance Addictions. Int J Environ Res Public Health 2018 Apr 04;15(4) [FREE Full text] [doi: 10.3390/ijerph15040676] [Medline: 29617325]

20. Field M, Christiansen P. Commentary on Ataya et al. (2012), 'Internal reliability of measures of substance-related cognitive bias'. Drug and Alcohol Dependence 2012 Aug;124(3):189-190. [doi: 10.1016/j.drugalcdep.2012.02.009] 
21. Field M. ; Mogg, K. ; Bradley, B. P. Cognitive bias and drug craving in recreational cannabis users.Drug Alcohol Depend,74, 105 2004:111.

22. Field M. Cannabis 'dependence' and attentional bias for cannabis-related words. Behav. Pharmacol,16, 473? $2005: 476$.

23. Constantinou N, Morgan CJA, Battistella S, O'Ryan D, Davis P, Curran HV. Attentional bias, inhibitory control and acute stress in current and former opiate addicts. Drug Alcohol Depend 2010 Jun 01;109(1-3):220-225. [doi:

10.1016/j.drugalcdep.2010.01.012] [Medline: 20172662]

24. Frankland L, Bradley BP, Mogg K. Time course of attentional bias to drug cues in opioid dependence. Psychol Addict Behav 2016 Aug;30(5):601-606. [doi: 10.1037/adb0000169] [Medline: 27031089]

25. Garland E, Howard MO. Opioid attentional bias and cue-elicited craving predict future risk of prescription opioid misuse among chronic pain patients. Drug Alcohol Depend 2014 Nov 01;144:283-287 [FREE Full text] [doi: 10.1016/j.drugalcdep.2014.09.014] [Medline: 25282309]

26. Garland E, Froeliger BE, Passik SD, Howard MO. Attentional bias for prescription opioid cues among opioid dependent chronic pain patients. J Behav Med 2013 Dec;36(6):611-620 [FREE Full text] [doi: 10.1007/s10865-012-9455-8] [Medline: 22968666]

27. Noël X, Colmant M, Van Der Linden M, Bechara A, Bullens Q, Hanak C, et al. Time course of attention for alcohol cues in abstinent alcoholic patients: the role of initial orienting. Alcohol Clin Exp Res 2006 Nov;30(11):1871-1877. [doi: 10.1111/j.1530-0277.2006.00224.x] [Medline: 17067351]

\section{Abbreviations \\ ASI: Addiction Severity Index \\ SDS: Severity of Drug Dependence Scale \\ SF-12: Short Form 12-item questionnaire}

Edited by G Eysenbach; submitted 19.09.19; peer-reviewed by R Ho, T Klose; comments to author 09.10.19; revised version received
09.10.19; accepted 17.10.19; published 12.11.19
Please cite as:
Zhang M, Ying J, Amron SB, Mahreen Z, Song G, Fung DSS, Smith HE
Making Sense of Negative Findings from Mobile Attention Bias Modification Interventions for Individuals with Addictive Disorders:
Quantitative Feasibility Study
JMIR Mhealth Uhealth 2019;7(11):e16325
URL: $\underline{\text { http://mhealth.jmir.org/2019/11/e16325/ }}$
doi: $10.2196 / 16325$
PMID: $\underline{31714248}$

CMelvyn Wb Zhang, Jiangbo Ying, Syidda B Amron, Zaakira Mahreen, Guo Song, Daniel SS Fung, Helen E Smith. Originally published in JMIR Mhealth and Uhealth (http://mhealth.jmir.org), 12.11.2019. This is an open-access article distributed under the terms of the Creative Commons Attribution License (https://creativecommons.org/licenses/by/4.0/), which permits unrestricted use, distribution, and reproduction in any medium, provided the original work, first published in JMIR mhealth and uhealth, is properly cited. The complete bibliographic information, a link to the original publication on http://mhealth.jmir.org/, as well as this copyright and license information must be included. 